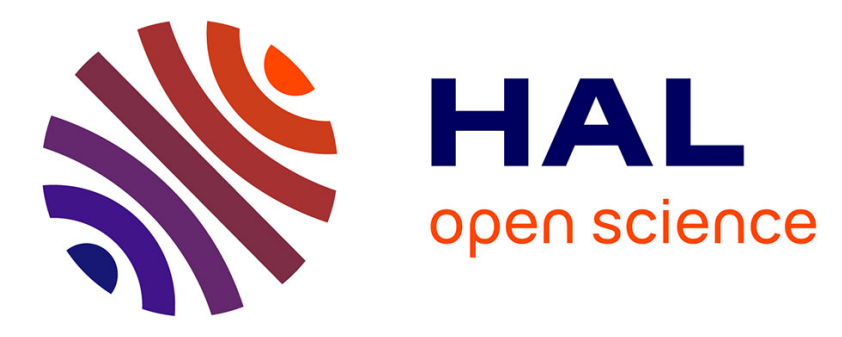

\title{
Brain injury during venovenous extracorporeal membrane oxygenation
}

\author{
Charles-Edouard Luyt, Nicolas Bréchot, Pierre Demondion, Tamara \\ Jovanovic, Guillaume Hékimian, Guillaume Lebreton, Ania Nieszkowska, \\ Matthieu Schmidt, Jean-Louis Trouillet, Pascal Leprince, et al.
}

\section{To cite this version:}

Charles-Edouard Luyt, Nicolas Bréchot, Pierre Demondion, Tamara Jovanovic, Guillaume Hékimian, et al.. Brain injury during venovenous extracorporeal membrane oxygenation. Intensive Care Medicine, 2016, 42 (5), pp.897-907. 10.1007/s00134-016-4318-3 . hal-01302501

\section{HAL Id: hal-01302501 https: / hal.sorbonne-universite.fr/hal-01302501}

Submitted on 14 Apr 2016

HAL is a multi-disciplinary open access archive for the deposit and dissemination of scientific research documents, whether they are published or not. The documents may come from teaching and research institutions in France or abroad, or from public or private research centers.
L'archive ouverte pluridisciplinaire HAL, est destinée au dépôt et à la diffusion de documents scientifiques de niveau recherche, publiés ou non, émanant des établissements d'enseignement et de recherche français ou étrangers, des laboratoires publics ou privés. 


\section{Brain Injury during Venovenous Extracorporeal Membrane}

\section{Oxygenation}

Charles-Edouard Luyt ${ }^{1,2}$, Nicolas Bréchot ${ }^{1,2}$, Pierre Demondion ${ }^{3}$, Tamara Jovanovic ${ }^{1}$, Guillaume Hékimian $^{1,2}$, Guillaume Lebreton ${ }^{3}$, Ania Nieszkowska ${ }^{1,2}$, Matthieu Schmidt ${ }^{1,2}$, Jean-Louis Trouillet $^{1,2}$, Pascal Leprince ${ }^{3}$, Jean Chastre ${ }^{1,2}$, and Alain Combes ${ }^{1,2}$

${ }^{1}$ Service de Réanimation, Institut de Cardiologie, Groupe Hospitalier Pitié-Salpêtrière, Assistance Publique-Hôpitaux de Paris, Paris, France; ${ }^{2}$ Sorbonne Universités, UPMC Université Paris 06, INSERM, UMRS_1166-ICAN Institute of Cardiometabolism and Nutrition, Paris, France; ${ }^{3}$ Service de Chirurgie Thoracique et Cardiovasculaire, Institut de Cardiologie, Groupe Hospitalier Pitié-Salpêtrière, Assistance Publique-Hôpitaux de Paris, Paris, France.

Correspondence and requests for reprints should be sent to Charles-Edouard Luyt, M.D., Ph.D., Service de Réanimation, ICAN, Groupe Hospitalier Pitié-Salpêtrière, 47-83, boulevard de l'Hôpital, 75651 Paris Cedex 13, France. Tel: +33 (0)1 421638 24; Fax: +33 (0)1 421638 17; Email: charles-edouard.luyt@psl.aphp.fr Author Contributions: C.-E.L., J.C. and A.C. initiated and designed the study. All authors contributed to the acquisition of the data, data analysis and the writing of the manuscript, and approved the final version.

Funding/Support: None.

Short Running Head: Brain injury during venovenous-ECMO

Word count: 3242 words

Keywords: extracorporeal membrane oxygenation; acute lung injury; intracranial brain hemorrhage; cerebral stroke; hypercapnia 
ICME-D-15-01605_R2 clean copy. Luyt et al., Brain injury during VV-ECMO

\begin{abstract}
Purpose: The frequency of neurological events and their impact on patients receiving venovenous-extracorporeal membrane oxygenation (VV-ECMO) are unknown. We therefore study the epidemiology, risk factors and impact of cerebral complications occurring in VVECMO patients.
\end{abstract}

Methods: Observational study conducted in a tertiary referral center (2006-2012) on patients developing a neurological complication (ischemic stroke or intracranial bleeding) while on VV-ECMO versus those who did not, and systematic review on this topic.

Results: Among 135 consecutive patients having received VV-ECMO, 18 (15 assessable) developed cerebral complications on ECMO: cerebral bleeding in 10 (7.5\%), ischemic stroke in $3(2 \%)$ or diffuse microbleeds in $2(2 \%)$, occurring after respective medians (IQR) of 3 (111), 21 (10-26) and 36 (8-63) days post-ECMO onset. Intracranial bleeding was independently associated with renal failure at intensive care unit admission and rapid $\mathrm{PaCO}_{2}$ decrease at ECMO initiation, but not with age, comorbidities or hemostasis disorders. Seven (70\%) patients with intracranial bleeding and one (33\%) with ischemic stroke died versus $40 \%$ of patients without neurological event. Systematic review found comparable intracranial bleeding rates $(5 \%)$.

Conclusions: Neurological events occurred frequently in patients on VV-ECMO. Intracranial bleeding, the most frequent, occurred early and was associated with higher mortality. Because it was independently associated with rapid hypercapnia decrease, the latter should be avoided at ECMO onset, but its exact role remains to be determined. These findings may have major implications for the care of patients requiring VV-ECMO.

\title{
Abstract word count: 237 words
}


ICME-D-15-01605_R2 clean copy. Luyt et al., Brain injury during VV-ECMO

The use of venovenous-extracorporeal membrane oxygenation (VV-ECMO) to treat patients with refractory acute respiratory distress syndrome (ARDS) has increased in recent years [1, 2]. Among complications occurring during ECMO support, neurological injury is important because it may be associated with increased mortality and long-term functional sequelae. In the landmark observational study on VV-ECMO for refractory ARDS complicating H1N1v2009 influenza, most deaths were attributed to cerebral hemorrhage [3]. To date, only two studies have specifically investigated neurological complications of ECMO support and both showed high numbers of brain injuries $[4,5]$. However, those observational studies concerned patients receiving venoarterial-ECMO (VA-ECMO) and most subjects were included after cardiac surgery or cardiac arrest. VV-ECMO neurological complications have mostly been reported as case reports $[6,7]$.

Because no epidemiological data on neurological complications occurring during VVECMO are available, we undertook this retrospective study on information prospectively collected from a large series of VV-ECMO patients to describe the frequency, morbidity, mortality and risk factors of cerebral injury. We then conducted a systematic review of all reported neurological complications in VV-ECMO series.

\section{METHODS}

All patients admitted to our intensive care unit (ICU) from 2006 to 2012 who received VVECMO support were included. Because circulatory assistance of any type can be complicated by thromboembolic phenomena, particularly cerebral infarction due to embolism, we excluded patients having received a VA-ECMO (peripheral or central), a left ventricle assist device (VAD), a BiVAD or a total artificial heart before, during or after VV-ECMO run. Thus, patients switched from VA-ECMO to VV-ECMO or from VV- to VA-ECMO were excluded. Clinical information on medical history, clinical and biological parameters at ICU 
ICME-D-15-01605_R2 clean copy. Luyt et al., Brain injury during VV-ECMO

admission and during the stay was collected prospectively. In particular, any events occurring during ECMO support were prospectively recorded in the ICU's database.

We defined clinical neurological complication as any clinical event occurring during ECMO course. It included any clinical sign suggestive of stroke (hemiplegia, mydriasis, anisocoria, asymmetry on clinical examination), but also confusion, delirium, seizures, coma despite sedation withdrawal. Patients were categorized according to the presence or not of brain injury on brain imaging (i.e. no brain damage, ischemic stroke, intracranial bleeding and microbleeds) and groups were compared.

\section{ECMO Circuit}

The extracorporeal system consisted of polyvinyl chloride tubing, a membrane oxygenator (QuadroxBioline, Jostra-Maquet, Orléans, France, or Eos ECMO, Sorin, Milan, Italy), a centrifugal pump (Rotaflow, Jostra-Maquet, or Revolution, Sorin), and drainage and reinfusion cannulae (Biomedicus Carmeda, Medtronic, Boulogne-Billancourt, France, or Edwards Lifesciences, Irvine, CA). An oxygen-air blender (Sechrist Industries, Anaheim, CA) was used to ventilate the membrane oxygenator. All patients had two-site cannulation and all cannulae were inserted percutaneously. The drainage cannula was inserted into the femoral vein (extending into the inferior vena cava) and the reinfusion cannula was inserted into the internal jugular vein (extending into the right atrium).

\section{Patient Management under ECMO}

All patients had a blood gas analysis in the 2 hours preceding ECMO start (blood gas analysis pre-ECMO) and in the 2 hours following ECMO start (blood gas analysis post-ECMO).

All patients had the same protocol for anticoagulation. A heparin bolus (5000 IU) was injected at ECMO initiation; then all patients were continuously infused with unfractionated 
ICME-D-15-01605_R2 clean copy. Luyt et al., Brain injury during VV-ECMO

heparin. The heparin dose was adapted at least once daily according to activated partial thrombin time (aPTT) value (targeting 1 to 1.5 -fold the control value) and clinical tolerance; heparin was stopped when bleeding occurred and restarted once it was controlled. Bleeding leading to heparin withdrawal was defined as any clinical bleeding judged significant by the physician in charge of the patient (at ECMO site, central or arterial lines, tracheal secretions, ear nose and throat) with or without hemodynamic impact, with or without decrease in haemoglobin level. Anticoagulant overdose was defined biologically as an aPTT (patient/control) ratio $>2.5$, corresponding to an absolute value of $\geq 80 \mathrm{~s}$.

Membrane oxygenator and circuitry were checked daily by experienced perfusionists and were changed when fibrin deposition or thrombi had deleterious effects on blood oxygenation, platelet count $(<20,000 / \mathrm{ml})$ or blood fibrinogen level $(<1.5 \mathrm{~g} / \mathrm{L})$ decreased significantly, or significant intravascular hemolysis (free plasma haemoglobin $>200 \mathrm{mg} / \mathrm{L}$ at 2 time points and no other cause of mechanical hemolysis) appeared. No systematic circuit change was scheduled.

Daily routine neurologic examinations were performed in our patients by the physicians and the nurses in charge of the patient. Physicians performed at least once daily neurologic examination after sedation withdrawal, including Glasgow coma scale calculation, response to verbal orders or pain, tendon reflexes, brainstem reflexes and plantar reflex, eye opening and pupils' examination. Size of pupils and their light reactivity were assessed by the nurse in charge of the patient every 4 hours. Moreover, when an unexpected event occurred (such as seizures, delirium confusion, no awakening after sedation withdrawal...), this was registered in the medical chart. Once a neurologic symptom was observed (including but not restricted to change in neurological exam, mydriasis, anisocoria, seizures, delirium, confusion, coma despite sedation withdrawal...) within 6 hours a cerebral CT scan was performed. 
ICME-D-15-01605_R2 clean copy. Luyt et al., Brain injury during VV-ECMO

\section{Literature Review}

We conducted a systematic MEDLINE-Database literature review through the PubMed search engine with a global search strategy applying prespecified selection and outcome (occurrence of neurological complication and mortality) criteria using the terms ECMO, venovenousECMO and extracorporeal oxygenation. Details on methodology and the results of this review are presented in an Online Supplemental Data.

\section{Statistical Analyses}

Data are expressed as medians $\left[25^{\text {th }}-75^{\text {th }}\right.$ percentile interquartile range (IQR) $]$ or means $( \pm$ standard deviation (SD)), as appropriate. Between-group comparisons were analyzed using Student's $t$-test or the Mann-Whitney $U$-test for continuous variables, chi-square test for categorical variables. For dichotomous variables, the median value was chosen for the cut-off to separate the variable into two categories. To examine the univariable impact of patients' clinical characteristics and ICU events on the development of cerebral bleeding, a logisticregression model tested each characteristic. Thereafter, multivariable analysis with a Cox regression model compared the factors that were significant in the univariable analysis. The analysis was run using backward-stepwise variable elimination (with the variable-exit threshold set at $P>0.05)$. Risk factors achieving $P \leq 0.10$ in our univariable analysis and parameters previously reported to be strongly associated with intracranial bleeding were entered into the model. Interactions were tested in the model; variables strongly associated with other(s) were not included in the multivariable model. The final model included renal failure on admission, $\mathrm{PaO} 2$ change and $\mathrm{PaCO} 2$ change. In a sensitivity analysis, lowest platelets count, lowest fibrinogen level and lowest prothrombin time were added to the final 
ICME-D-15-01605_R2 clean copy. Luyt et al., Brain injury during VV-ECMO

model for intracranial bleeding. Two other endpoints were investigated using Cox regression model: ICU mortality without intracranial bleeding, and a composite endpoint; intracranial bleeding or ICU mortality. Analyses were computed with StatView v5.0 (SAS Institute Inc, Cary, NC) and SPSS v11.5 (SPSS Inc, Chicago, IL) software. $P<0.05$ defined significance.

\section{Ethics}

In accordance with the ethical standards of our hospitals institutional review boards (Committee for the Protection of Human Subjects), informed consent for demographic, physiological and hospital-outcome data analyses was not obtained because this observational study did not modify existing diagnostic or therapeutic strategies.

\section{RESULTS}

During the study period, 135 patients required VV-ECMO support. Table 1 reports their baseline characteristics. For 23 of those 135 patients, a cerebral event could not be ruled out because they died before neurological examination could be performed or had preexisting neurological disease. A clinical neurological symptom appeared in 25 (19\%) during VVECMO support (Figure 1). Three of those 25 were clinically brain dead, confirmed by electroencephalogram, and did not undergo cerebral imaging; therefore, hemorrhagic stroke could not be excluded.

Brain imaging was obtained for the remaining 22 patients (computed-tomography (CT) scan for 21 and magnetic resonance imaging (MRI, performed after ECMO removal) for one), and five other patients without any clinical signs underwent cerebral CT scans (for one of them with traumatic brain injury, the CT scan was obtained for follow-up) (Figure 1). Cerebral-imaging findings as a function of clinical neurological feature(s) are given in Table 2. Cerebral-imaging sequences for 10 patients were normal; 10 patients had intracranial 
ICME-D-15-01605_R2 clean copy. Luyt et al., Brain injury during VV-ECMO

bleeding, either intraparenchymal hematoma $(n=9)$ or subarachnoid hemorrhage $(n=1)$; three patients had ischemic strokes; two patients had diffuse microbleeds and two patients had brain edema (for the latter, the neurological injury preceded ECMO: one suffered traumatic brain injury 7 days before ECMO with cerebral edema before ECMO; the other had prolonged cardiac arrest 2 days pre-ECMO and cerebral edema was attributed to cerebral anoxia).

Thus, $18(13 \%, 95 \%$ CI $7.3-18.7 \%)$ of the 135 patients had a cerebral complication that occurred while on ECMO (three brain deaths without imaging, 10 intracranial bleeds, three ischemic strokes and two diffuse microbleeds). Table 1 gives patients' characteristics as a function of the type of neurological event occurring on ECMO or not. Patients with such complications were older and more frequently had renal failure at ICU admission (especially patients with intracranial bleeding) than those without these events. Other parameters did not differ between groups, although patients with intracranial bleeding tended to have higher mortality and shorter time from ECMO onset to neurological complications.

\section{Patients with Intracranial Bleeding}

Because the predominant neurological event was intracranial bleeding, we specifically analyzed those 10 patients to attempt to identify risk factors associated with this complication. Figure 2 reports the $\mathrm{pH}, \mathrm{PaCO}_{2}$ and $\mathrm{PaO}_{2}$ changes between just before and after starting ECMO in patients with and without intracranial bleeding. Comparing patients without to those with cerebral bleeding, respectively, the latter had higher $\mathrm{PaO}_{2}$ increases just after ECMO onset (medians [IQR]: 20 [4.7-52] vs. 58 [19-214] mmHg; $P=0.04$ ), a not significant $\mathrm{PaCO}_{2}$ decrease just after ECMO initiation ( -24 [ -15 to -38$]$ vs. -33 [ -28 to -38$]$ $\mathrm{mmHg} ; P=0.06)$ but no $\mathrm{pH}$ change difference just after starting ECMO $(0.17[0.09-0.26]$ vs. $0.26[0.12-0.29] ; P=0.26)$. 
ICME-D-15-01605_R2 clean copy. Luyt et al., Brain injury during VV-ECMO

Table 3 reports the factors associated with intracranial bleeding. Renal failure at ICU admission, $\mathrm{PaO}_{2}$ increase just after ECMO initiation $>50 \mathrm{mmHg}$ and $\mathrm{PaCO}_{2}$ decrease just after ECMO onset $<-27 \mathrm{mmHg}$ were the only factors significantly associated with brain hemorrhage in the univariable analysis, whereas the Cox analysis retained renal failure at ICU admission and $\mathrm{PaCO}_{2}$ decrease as the only factors independently associated with intracranial bleeding. Absolute baseline values of $\mathrm{PaO} 2$ and $\mathrm{PaCO} 2$ were not associated with intracranial bleeding. Age, female sex and mechanical ventilation duration pre-ECMO showed a trend towards association with intracranial bleeding. Hemostasis disorders were not associated with intracranial bleeding in uni-or-multivariable analyses (sensitivity analysis not shown). Table 4 lists the hemostasis-parameter values 3 days before brain injury. These patients' heparin doses were low, as were their aPPT values and anti-Xa activity, and none had profound thrombopenia or low fibrinogen levels.

Same risk factors were associated with an increased risk of both death and the composite endpoint (Online Supplement, Tables E1 and E2). Among them, $\mathrm{PaCO}_{2}$ change and lowest prothrombin time during EMCO, but not renal failure, were associated with ICU mortality (Online Supplement, Tables E1 and E2).

\section{DISCUSSION}

We report here the largest study to date of neurological complications during VV-ECMO. We found that 25 of our 135 patients (19\%) experienced a clinical neurological event, with 18 (13\%, 95\% CI 7.3-18.7\%) of those neurological injuries occurring on VV-ECMO. Cerebral bleeding was the predominant complication, manifesting as coma or mydriasis. Intriguingly, it was not associated with hemostasis disorders or anticoagulant use: platelet counts, prothrombin time, aPPT and fibrinogen levels while on ECMO were similar among patients 
ICME-D-15-01605_R2 clean copy. Luyt et al., Brain injury during VV-ECMO

with and without cerebral hemorrhage, and heparin doses during the 3 days preceding cerebral bleeding were low, without overdose. The only factors independently associated with brain hemorrhage were renal failure at ICU admission and acute $\mathrm{PaCO}_{2}$ changes at ECMO initiation.

Our results are in accordance with the literature on neurological complications occurring in ECMO patients (Table 5). Kasirajan et al. reported $18.9 \%$ intracranial bleeding for their series of 74 VA-ECMO patients. In that study, cerebral bleeding was independently associated with female sex and thrombocytopenia. Mateen et al. retrospectively studied 87 VA-ECMO patients and found a high rate of neurological injury, including stroke, intracranial bleeding and brain death [5]; the 10 brains examined at autopsy revealed more neurological sequelae than would have been predicted by clinical findings alone. However, that study included VA-ECMO patients after cardiac surgery or cardiac arrest. The authors of the largest study that included 23,951 patients given ECMO support reported $10.9 \%$ neurological complications [13]. Ischemic stroke, cerebral bleeding and seizure frequencies were $4.1 \%$, $3.6 \%$ and $4.1 \%$, respectively, but, as underlined by the authors themselves, they mixed adults, children and newborns, and were unable to distinguish patients receiving VV- and/or VAECMO [13]. The cerebral bleeding frequency for VV-ECMO patients observed in the systematic review (see online supplement) was 5\%, similar to ours. However, this systematic review has several limitations: first, among the 16 studies reporting neurological complications of ECMO, most of them mixed VV- and VA-ECMO. Thus, the exact cerebral complication frequency of VV-ECMO is difficult to calculate precisely. Another limitation is that most previous studies reported only cerebral bleeding and no other neurological complications, e.g. ischemic stroke. Lastly, unlike our investigation, those studies had not been designed to evaluate factors associated with neurological complications.

The pathophysiology of VA-ECMO- or VV-ECMO-associated brain injury probably 
ICME-D-15-01605_R2 clean copy. Luyt et al., Brain injury during VV-ECMO

differs. In VA-ECMO patients, brain damage could reflect the pre-ECMO clinical context (low blood pressure and cerebral blood flow, hypoxia, acidosis, electrolyte disturbances, and/or hemostasis disorders related to hepatic failure frequently observed in cardiogenic shock), reperfusion injury at ECMO implantation, the ECMO process itself (embolic stroke from the arterial cannula) and/or hemostasis disorders induced by the ECMO circuit. To date, the exact mechanism of brain damage is not fully understood and probably includes a combination of all those factors.

In VV-ECMO patients, a combination of factors also probably leads to neurological complications, even though some of these factors are not strictly the same. Whereas disorders created by the ECMO circuit and the oxygenator (hemolysis, thrombocytopenia, fibrinolysis, acquired von Willebrand syndrome [14]) are the same in VA- and VV-ECMO, pre-ECMO factors and ECMO-induced metabolic changes could differ. The pre-ECMO factors include hypoxia, hypercapnia, respiratory acidosis and parameters associated with acute respiratory failure before starting support. VV-ECMO specificities include abrupt $\mathrm{O}_{2}$ and $\mathrm{CO}_{2}$ changes at ECMO onset $[15,16]$. Because $\mathrm{CO}_{2}$ is involved in the regulation of cerebral blood flow [17, 18], sudden $\mathrm{CO}_{2}$-level changes (from hypercapnia to normocapnia or hypocapnia) at ECMO initiation could have induced sudden cerebral blood-flow changes that could have precipitated brain damage. Recently, Muellenbach et al. reported that patients receiving vvECMO treatment were at risk for a decrease in cerebral regional tissue oxygen saturation at ECMO initiation, and that this decreased is linked to $\mathrm{PaCO} 2$ change. This could be involved in the pathogenesis of brain injury of ECMO patients $[19,20]$. In our study, the acute $\mathrm{PaCO}_{2}$ change was independently associated with cerebral bleeding and one can hypothesize that these abrupt changes may have facilitated brain hemorrhages. Although we have no definite proof of this association, we think it should be taken into account when initiating VV-ECMO and in our ICU we have now changed our practice by trying to avoid too rapid hypercapnia 
ICME-D-15-01605_R2 clean copy. Luyt et al., Brain injury during VV-ECMO

correction. It could be achieved by starting with a low sweep gas flow and progressively increasing it over time. Even though $\mathrm{PaO}_{2}$ change was not independently associated with cerebral bleeding, it can be recommended not to correct it too quickly by starting with a low fraction of inspired oxygen and increasing it slowly over time. However, because rapid decrease in $\mathrm{PaCO} 2$ leads to vasoconstriction, the relationship between $\mathrm{PaCO} 2$ change and cerebral bleeding is difficult to understand. We cannot exclude that ECMO-induced alkalosis have caused microbleeds or excessive local flow with altered brain blood barrier and bleeding.

Surprisingly, hemostasis disorders were not associated with intracranial bleeding herein. However, because lowest prothrombin time while on ECMO was strongly associated with an increased risk of mortality, the lack of association between lowest prothrombin time and intracranial bleeding could be an indirect effect of the increased mortality among patients presenting this risk factor. Moreover, because our patients' platelet function was not explored, we cannot exclude that those with intracranial haemorrhage might have had platelet dysfunction. Our patients received relatively low dose of heparin, but this is explained by our anticoagulation policy; we target an aPTT ratio of 1 to 1.5 , and stop heparin when clinical bleeding occurs. Although hemostasis disorders could have played a role, the mechanism of cerebral bleeding in those patients is probably multifactorial, including vascular injury due to underlying disease severity, disorders created by the ECMO circuit (hemolysis, fibrinolysis...), rapid $\mathrm{PaO}_{2}$ and $\mathrm{PaCO}_{2}$ changes and other, as yet unknown, factors. Future studies should investigate the precise mechanisms that could precipitate neurological complications, particularly controllable factors like $\mathrm{PaO}_{2}$ and $\mathrm{PaCO}_{2}$ changes.

Our study has several limitations. First, this was a single-center study and, although we included many VV-ECMO patients, not many developed neurological events. Thus, our results, particularly the role of rapid gas exchange parameter changes in cerebral bleeding, 
ICME-D-15-01605_R2 clean copy. Luyt et al., Brain injury during VV-ECMO

will have to be confirmed by larger studies. Moreover, because the delivery of ECMO is so variable from centre to centre (devices used, techniques employed; management of anticoagulation and transfusion, thresholds for addressing hypoxemia, and so on), these results would be difficult to extrapolate to other centres. Second, although it is our policy to carefully check hemostasis parameters in patients on VV-ECMO, we did not examine hemostasis, specifically thrombosis and fibrinolysis, with thromboelastogram, D-dimer or other tests [21]. Because it is well-known that ECMO patients have primary hemostasis disorders (e.g., acquired von Willebrand disease [14]), we cannot exclude the possibility of unrecognized hemostasis disorders that might explain the high intracranial bleeding frequency. Third, because it was difficult to assess neurological status at ICU admission, it is possible that, at least in some patients, neurological complications may have preceded ECMO and that ECMO aggravated them. However, albeit impossible to demonstrate, it is not likely, since our policy is to carefully check daily for clinical signs of brain involvement, in particular at ICU admission. Fourth, because 23 patients could not be evaluated before dying and because we also cannot exclude that some patients might have had an undetected neurological injury, we may have underestimated the exact frequency of brain injury, as in most studies published to date and reporting neurological outcomes. Fifth, because neuroimaging was not performed in all patients, we could have underestimated the frequency of neurological injury (missing subclinical events). Sixth, we found no direct association between hemostasis disorders and intracranial bleeding, but lowest prothrombin time while on ECMO was strongly associated with ICU mortality. This lack of association between lowest prothrombin time and intracranial bleeding could be an indirect effect of the increased mortality among patients presenting this risk factor. Lastly, we identified 2 conditions associated with cerebral bleeding during ECMO, but their relationships with brain haemorrhage remain unknown: are they causative factors or merely coincidental? Moreover, 
ICME-D-15-01605_R2 clean copy. Luyt et al., Brain injury during VV-ECMO

we explored only the blood gas change at ECMO start, not during the whole ECMO course. We therefore cannot be sure that rapid change of $\mathrm{PaO} 2 / \mathrm{PaCO} 2$ could have occurred after several hours or days and could have play a role in brain injury. Future studies should explore these possibilities.

In conclusion, neurological complications are frequent in patients on VV-ECMO. Intracranial bleeding, the most frequent event, occurred early during ECMO and was associated with high mortality. The precise roles of sudden $\mathrm{O}_{2-}$ and $\mathrm{CO}_{2}$-level changes need to be more precisely evaluated, not only for the sake of knowledge, but mainly because they might have major implications in the care of patients requiring VV-ECMO.

Acknowledgment: The authors thank Janet Jacobson for editorial assistance in revising the manuscript and Marguerite Guiguet for statistical assistance.

Conflicts of Interest: Alain Combes is the primary investigator of the EOLIA, NCT07470703, a randomized trial of VV-ECMO supported in part by MAQUET. Alain Combes has received honoraria for lectures by MAQUET, BAXTER, and ALUNG. Other authors declare that they have no conflict of interest related to the purpose of this manuscript. 
ICME-D-15-01605_R2 clean copy. Luyt et al., Brain injury during VV-ECMO

\section{References}

1. Luyt CE, Combes A, Becquemin MH, Beigelman-Aubry C, Hatem S, Brun AL, Zraik N, Carrat F, Grenier PA, Richard JC, Mercat A, Brochard L, Brun-Buisson C,Chastre J (2012) Long-term outcomes of pandemic 2009 influenza A (H1N1)-associated severe acute respiratory distress syndrome. Chest 142:583-592.

2. Combes A, Brodie D, Bartlett R, Brochard L, Brower R, Conrad S, De Backer D, Fan E, Ferguson N, Fortenberry J, Fraser J, Gattinoni L, Lynch W, MacLaren G, Mercat A, Mueller T, Ogino M, Peek G, Pellegrino V, Pesenti A, Ranieri M, Slutsky A,Vuylsteke A (2014) Position paper for the organization of extracorporeal membrane oxygenation programs for acute respiratory failure in adult patients. Am J Respir Crit Care Med 190: 488-96.

3. Davies A, Jones D, Bailey M, Beca J, Bellomo R, Blackwell N, Forrest P, Gattas D, Granger E, Herkes R, Jackson A, McGuinness S, Nair P, Pellegrino V, Pettila V, Plunkett B, Pye R, Torzillo P, Webb S, Wilson M,Ziegenfuss M (2009) Extracorporeal Membrane Oxygenation for 2009 Influenza A(H1N1) Acute Respiratory Distress Syndrome. JAMA 302: $1888-95$.

4. Kasirajan V, Smedira NG, McCarthy JF, Casselman F, Boparai N,McCarthy PM (1999) Risk factors for intracranial hemorrhage in adults on extracorporeal membrane oxygenation. Eur J Cardiothorac Surg 15: 508-14.

5. Mateen FJ, Muralidharan R, Shinohara RT, Parisi JE, Schears GJ,Wijdicks EF (2011) Neurological injury in adults treated with extracorporeal membrane oxygenation. Arch Neurol 68: 1543-9.

6. Chow FC, Edlow BL, Frosch MP, Copen WA,Greer DM (2011) Outcome in patients with H1N1 influenza and cerebrovascular injury treated with extracorporeal membrane oxygenation. Neurocrit Care 15: 156-60. 
ICME-D-15-01605_R2 clean copy. Luyt et al., Brain injury during VV-ECMO

7. Le Guennec L, Bertrand A, Laurent C, Roze H, Chastre J, Combes A,Luyt CE (2015) Diffuse cerebral microbleeds after extracorporeal membrane oxygenation support. Am J Respir Crit Care Med 191: 594-6.

8. McHorney CA, Ware JE, Jr., Lu JF,Sherbourne CD (1994) The MOS 36-item Short-Form Health Survey (SF-36): III. Tests of data quality, scaling assumptions, and reliability across diverse patient groups. Med Care 32: 40-66.

9. Zigmond AS,Snaith RP (1983) The hospital anxiety and depression scale. Acta Psychiatr Scand 67: 361-70.

10. Stoll C, Kapfhammer HP, Rothenhausler HB, Haller M, Briegel J, Schmidt M, Krauseneck T, Durst K,Schelling G (1999) Sensitivity and specificity of a screening test to document traumatic experiences and to diagnose post-traumatic stress disorder in ARDS patients after intensive care treatment. Intensive Care Med 25: 697-704.

11. Trouillet JL, Luyt CE, Guiguet M, Ouattara A, Vaissier E, Makri R, Nieszkowska A, Leprince P, Pavie A, Chastre J,Combes A (2011) Early percutaneous tracheotomy versus prolonged intubation of mechanically ventilated patients after cardiac surgery: a randomized trial. Ann Intern Med 154: 373-83.

12. Schmidt M, Zogheib E, Roze H, Repesse X, Lebreton G, Luyt CE, Trouillet JL, Brechot N, Nieszkowska A, Dupont H, Ouattara A, Leprince P, Chastre J,Combes A (2013) The PRESERVE mortality risk score and analysis of long-term outcomes after extracorporeal membrane oxygenation for severe acute respiratory distress syndrome. Intensive Care Med 39: 1704-13.

13. Nasr DM,Rabinstein AA (2015) Neurologic Complications of Extracorporeal Membrane Oxygenation. J Clin Neurol 11:383-389. 
ICME-D-15-01605_R2 clean copy. Luyt et al., Brain injury during VV-ECMO

14. Heilmann C, Geisen U, Beyersdorf F, Nakamura L, Benk C, Trummer G, Berchtold-Herz M, Schlensak C,Zieger B (2012) Acquired von Willebrand syndrome in patients with extracorporeal life support (ECLS). Intensive Care Med 38: 62-8.

15. Schmidt M, Tachon G, Devilliers C, Muller G, Hekimian G, Brechot N, Merceron S, Luyt CE, Trouillet JL, Chastre J, Leprince P,Combes A (2013) Blood oxygenation and decarboxylation determinants during venovenous ECMO for respiratory failure in adults. Intensive Care Med 39: 838-46.

16. Schmidt M, Pellegrino V, Combes A, Scheinkestel C, Cooper DJ,Hodgson C (2014) Mechanical ventilation during extracorporeal membrane oxygenation. Crit Care 18: 203.

17. Lassen NA,Christensen MS (1976) Physiology of cerebral blood flow. Br J Anaesth 48: 719-34.

18. Meng L,Gelb AW (2014) Regulation of Cerebral Autoregulation by Carbon Dioxide. Anesthesiology 122:196-205.

19. Muellenbach RM, Kilgenstein C, Kranke P, Kustermann J, Kredel M, Roewer N, Ernestus RI,Westermaier T (2014) Effects of venovenous extracorporeal membrane oxygenation on cerebral oxygenation in hypercapnic ARDS. Perfusion 29: 139-41.

20. Kredel M, Lubnow M, Westermaier T, Muller T, Philipp A, Lotz C, Kilgenstein C, Kustermann J, Roewer N,Muellenbach RM (2014) Cerebral tissue oxygenation during the initiation of venovenous ECMO. ASAIO J 60: 694-700.

21. Repesse X, Au SM, Brechot N, Trouillet JL, Leprince P, Chastre J, Combes A,Luyt CE (2013) Recombinant factor VIIa for uncontrollable bleeding in patients with extracorporeal membrane oxygenation: report on 15 cases and literature review. Crit Care 17: R55.

22. Kolla S, Awad SS, Rich PB, Schreiner RJ, Hirschl RB,Bartlett RH (1997) Extracorporeal life support for 100 adult patients with severe respiratory failure. Ann Surg 226: 544-64. 
ICME-D-15-01605_R2 clean copy. Luyt et al., Brain injury during VV-ECMO

23. Linden V, Palmer K, Reinhard J, Westman R, Ehren H, Granholm T,Frenckner B (2000) High survival in adult patients with acute respiratory distress syndrome treated by extracorporeal membrane oxygenation, minimal sedation, and pressure supported ventilation. Intensive Care Med 26: 1630-7.

24. Mols G, Loop T, Geiger K, Farthmann E,Benzing A (2000) Extracorporeal membrane oxygenation: a ten-year experience. Am J Surg 180: 144-54.

25. Hemmila MR, Rowe SA, Boules TN, Miskulin J, McGillicuddy JW, Schuerer DJ, Haft JW, Swaniker F, Arbabi S, Hirschl RB,Bartlett RH (2004) Extracorporeal life support for severe acute respiratory distress syndrome in adults. Ann Surg 240: 595-605.

26. Brogan TV, Thiagarajan RR, Rycus PT, Bartlett RH,Bratton SL (2009) Extracorporeal membrane oxygenation in adults with severe respiratory failure: a multi-center database. Intensive Care Med 35: 2105-14.

27. Peek GJ, Mugford M, Tiruvoipati R, Wilson A, Allen E, Thalanany MM, Hibbert CL, Truesdale A, Clemens F, Cooper N, Firmin RK,Elbourne D (2009) Efficacy and economic assessment of conventional ventilatory support versus extracorporeal membrane oxygenation for severe adult respiratory failure (CESAR): a multicentre randomised controlled trial. Lancet 374: 1351-63.

28. Noah MA, Peek GJ, Finney SJ, Griffiths MJ, Harrison DA, Grieve R, Sadique MZ, Sekhon JS, McAuley DF, Firmin RK, Harvey C, Cordingley JJ, Price S, Vuylsteke A, Jenkins DP, Noble DW, Bloomfield R, Walsh TS, Perkins GD, Menon D, Taylor BL,Rowan KM (2011) Referral to an extracorporeal membrane oxygenation center and mortality among patients with severe 2009 influenza A(H1N1). JAMA 306: 1659-68.

29. Patroniti N, Zangrillo A, Pappalardo F, Peris A, Cianchi G, Braschi A, Iotti GA, Arcadipane A, Panarello G, Ranieri VM, Terragni P, Antonelli M, Gattinoni L, Oleari F,Pesenti A (2011) The Italian ECMO network experience during the 2009 influenza 
ICME-D-15-01605_R2 clean copy. Luyt et al., Brain injury during VV-ECMO

A(H1N1) pandemic: preparation for severe respiratory emergency outbreaks. Intensive Care Med 37: 1447-57.

30. Pham T, Combes A, Roze H, Chevret S, Mercat A, Roch A, Mourvillier B, AraSomohano C, Bastien O, Zogheib E, Clavel M, Constan A, Marie Richard JC, BrunBuisson C,Brochard L (2103) Extracorporeal membrane oxygenation for pandemic influenza $\mathrm{A}(\mathrm{H} 1 \mathrm{~N} 1)$-induced acute respiratory distress syndrome: a cohort study and propensity-matched analysis. Am J Respir Crit Care Med 187: 276-85.

31. Lindskov C, Jensen RH, Sprogoe P, Klaaborg KE, Kirkegaard H, Severinsen IK, Lorentsen AG, Folkersen L, Ilkjaer S,Pedersen CM (2013) Extracorporeal membrane oxygenation in adult patients with severe acute respiratory failure. Acta Anaesthesiol Scand 57: 303-11.

32. Michaels AJ, Hill JG, Bliss D, Sperley BP, Young BP, Quint P, Shanks TR, Dalthorp J, Long WB,Morgan LJ (2013) Pandemic flu and the sudden demand for ECMO resources: a mature trauma program can provide surge capacity in acute critical care crises. J Trauma Acute Care Surg 74: 1493-7.

33. Roch A, Hraiech S, Masson E, Grisoli D, Forel JM, Boucekine M, Morera P, Guervilly C, Adda M, Dizier S, Toesca R, Collart F,Papazian L (2014) Outcome of acute respiratory distress syndrome patients treated with extracorporeal membrane oxygenation and brought to a referral center. Intensive Care Med 40: 74-83.

34. Ng GW, Leung AK, Sin KC, Au SY, Chan SC, Chan OP,Wu HH (2014) Three-year experience of using venovenous extracorporeal membrane oxygenation for patients with severe respiratory failure. Hong Kong Med J 20: 407-12.

35. Kon ZN, Dahi S, Evans CF, Byrnes KA, Bittle GJ, Wehman B, Rector RP, McCormick BM, Herr DL, Sanchez PG, Pham SM,Griffith BP (2015) Long-Term Venovenous 
ICME-D-15-01605_R2 clean copy. Luyt et al., Brain injury during VV-ECMO

Extracorporeal Membrane Oxygenation Support for Acute Respiratory Distress

Syndrome. Ann Thorac Surg 100:2059-63.

36. Gray BW, Haft JW, Hirsch JC, Annich GM, Hirschl RB,Bartlett RH (2015)

Extracorporeal life support: experience with 2,000 patients. ASAIO J 61: 2-7. 
ICME-D-15-01605_R2 clean copy. Luyt et al., Brain injury during VV-ECMO

\section{Figure Legends}

Figure 1. Flow chart of the study. VV-ECMO, venovenous-extracorporeal membrane oxygenation.

Figure 2. Gas exchange parameter changes at the start of venovenous-extracorporeal membrane oxygenation (VV-ECMO) in the 10 patients with intracranial bleeding (hatched boxes) and the remaining 125 (white boxes). (A) Absolute $\mathrm{pH}$ change defined as post-ECMOonset $\mathrm{pH}$ - pre-ECMO pH. (B) Absolute $\mathrm{PaCO}_{2}$ change defined as post-ECMO-onset $\mathrm{PaCO}_{2}-$ pre-ECMO $\mathrm{PaCO}_{2}$. (C) Absolute $\mathrm{PaO}_{2}$ change defined as post-ECMO-onset $\mathrm{PaO}_{2}$ - preECMO $\mathrm{PaO}_{2}$. The horizontal lines inside the box plots are the medians, the lower and upper limits of the box correspond to the $25^{\text {th }}$ and $75^{\text {th }}$ percentile interquartile ranges, the T-bars represent the $10^{\text {th }}$ and $90^{\text {th }}$ percentile interquartile ranges, and the circles are outliers. 
ICME-D-15-01605_R2 clean copy. Luyt et al., Brain injury during VV-ECMO

Table 1. Admission Characteristics, Hemostasis Disorders during VV-ECMO and Patient Outcomes According to Brain Damage

\begin{tabular}{|c|c|c|c|c|}
\hline \multirow[b]{2}{*}{ Characteristic } & \multirow{2}{*}{$\begin{array}{l}\text { No Brain } \\
\text { Damage } \\
(n=117)\end{array}$} & \multicolumn{3}{|c|}{ Patients with Brain Damage } \\
\hline & & $\begin{array}{l}\text { Intracranial } \\
\text { Bleeding } \\
(n=10)\end{array}$ & $\begin{array}{l}\text { Microbleeds } \\
\qquad(n=2)\end{array}$ & $\begin{array}{l}\text { Ischemic } \\
\text { Stroke } \\
(n=3)\end{array}$ \\
\hline Age, $\mathrm{yr}^{\mathrm{a}}$ & $44 \pm 14$ & $49 \pm 12$ & $54 \pm 4$ & $59 \pm 6$ \\
\hline Male sex, n (\%) & $79(68)$ & $5(50)$ & $2(100)$ & $1(33)$ \\
\hline Body mass index, $\mathrm{kg} / \mathrm{m}^{2}$ & $26[24-31]$ & $23[21-27]$ & $22[21-22]$ & $26[25-47]$ \\
\hline $\begin{array}{l}\text { McCabe \& Jackson } \\
\text { comorbidity score } \geq 2, \mathrm{n}(\%)\end{array}$ & $41(35)$ & $2(20)$ & 0 & $1(33)$ \\
\hline ICU-admission SAPS II score & $69 \pm 14$ & $71 \pm 12$ & $61 \pm 1$ & $71 \pm 9$ \\
\hline $\begin{array}{l}\text { H1N1v2009 influenza-related } \\
\text { ARDS, n }(\%)\end{array}$ & $18(15)$ & $1(10)$ & 0 & 0 \\
\hline $\begin{array}{l}\text { Duration of MV before ECMO, } \\
\text { days }\end{array}$ & $5[1-10]$ & $8[4-11]$ & $5[3-7]$ & $11[9-17]$ \\
\hline Organ failure at ECMO start ${ }^{\mathrm{b}}$ & & & & \\
\hline Cardiovascular & $30(25)$ & $2(20)$ & $1(50)$ & 0 \\
\hline Hepatic & $25(23)$ & $4(40)$ & 0 & 0 \\
\hline Renal $^{\mathrm{a}}$ & $48(41)$ & $8(80)$ & 0 & $2(67)$ \\
\hline Hematological & $15(13)$ & $1(10)$ & 0 & 0 \\
\hline Neurological & $94(80)$ & $8(80)$ & $1(50)$ & $3(100)$ \\
\hline Gas exchange values pre- & & & & \\
\hline ECMO & & & & \\
\hline Arterial $\mathrm{pH}$ & 7.26 & 7.18 [7.07- & $7.16[7.16-$ & $7.36[7.32-$ \\
\hline
\end{tabular}


ICME-D-15-01605_R2 clean copy. Luyt et al., Brain injury during VV-ECMO

$\begin{array}{ccccc} & {[7.16-} & 7.29] & 7.17] & 7.40] \\ & 7.34] & & & \\ \mathrm{PaCO}_{2} & 59[49-73] & 74[57-94] & 57[53-60] & 58[53-63] \\ \mathrm{PaO}_{2} & 55[47-68] & 68[66-75] & 86[42-129] & 61[55-67]\end{array}$

Gas exchange value post-

ECMO

Arterial pH

7.44

$[7.37-$

7.41-7.36-

$7.43[7.38-$

$7.52[7.35-$

7.45]

7.48]

7.57]

7.50]

$\mathrm{PaCO}_{2}$

$34[28.9-$

32 [30-47]

$31[20-41]$

36 [26-37]

38.7]

$\mathrm{PaO}_{2}$

$78[66-$

$154[101-$

$140[42-$

84 [63-125]

118]

257]

237]

Hemostasis disorders during

$\mathrm{ECMO}^{\mathrm{c}}$

Platelet count, $\times 10^{9} / \mathrm{L}$

46 [30-85]

59 [26-77]

$100[76-$

109 [50-177]

125]

Patients with platelets $<20$

$20(17)$

$2(20)$

0

0

$\times 10^{9} / \mathrm{L}, \mathrm{n}(\%)$

Patients with platelets

7 (6)

0

0

0

$<10 \times 10^{9} / \mathrm{L}, \mathrm{n}(\%)$

Prothrombin time, $\%$ of the $\quad 53[37-64] \quad 46[39-70] \quad 62[43-80] \quad 50[29-60]$ standard value
Patients with PT $<30 \%, \mathrm{n}$
$18(15)$
$1(10)$
0
$1(33)$

(\%) 
ICME-D-15-01605_R2 clean copy. Luyt et al., Brain injury during VV-ECMO
Patients with PT $<20 \%, \mathrm{n}$
$13(11)$
0
0
0

$(\%)$

Fibrinogen, g/L

$$
\text { Patients with fibrinogen }
$$

$<1.5 \mathrm{~g} / \mathrm{L}, \mathrm{n}(\%)$

Patients with fibrinogen $<1$

$16(14)$

$1(10)$

$1(50)$

$1(33)$

$\mathrm{g} / \mathrm{L}, \mathrm{n}(\%)$

Anticoagulant overdose, n (\%)

$15(13)$

Days of ECMO before

neurological event ${ }^{\mathrm{d}}$

Total duration of ECMO

support, days

ICU length of stay, days

Mortality, n (\%)

$2(20)$

$1(50)$

3.9]

$26(22)$

$3[1-11]$

$36[8-63]$
18 [8-30]

$45(38)$
$2.2[0.7-3.9]$

$10[6-25] \quad 3.5[2-6] \quad 29[3-54]$

$15[7-29]$

$21[11-26]$

Results are expressed as mean $\pm \mathrm{SD}$, number $(\%)$ or median $\left[27^{\text {th }}-75^{\text {th }}\right.$ percentile interquartile range].

Abbreviations: SAPS, Simplified Acute Physiology Score; VV-ECMO, venovenousextracorporeal membrane oxygenation; MV, mechanical ventilation; ARDS, acute respiratory distress syndrome; PT, prothrombin time; ICU, intensive care unit.

${ }^{\mathrm{a}} P<0.05$ for between-group comparisons.

${ }^{\mathrm{b}}$ Organ failure was deemed present when the corresponding Sepsis-related Organ Failure Assessment score was $>2$.

${ }^{\mathrm{c}}$ Worst value before or during ECMO.

${ }^{\mathrm{d}}$ Time of neurological event was calculated using the date of cerebral imaging 
ICME-D-15-01605_R2 clean copy. Luyt et al., Brain injury during VV-ECMO

Table 2. Cerebral Imaging Findings and Their Corresponding Clinical Features in the 22 Patients

\section{Cerebral Imaging Findings}

\begin{tabular}{|c|c|c|c|c|}
\hline Intracranial & Ischemic & Microbleeds & Cerebral & Normal \\
\hline Bleeding & Stroke & & Edema & \\
\hline
\end{tabular}

\begin{tabular}{lccccc} 
Clinical Picture & $(n=10)$ & $(n=3)$ & $(n=2)$ & $(n=2)$ & $(n=10)$ \\
Mydriasis & 6 & 1 & - & - & - \\
Coma & 2 & - & 2 & - & 3 \\
Brain death & - & - & - & 1 & - \\
Hemiplegia & 1 & 1 & - & - & - \\
Confusion & 1 & - & - & - & 1 \\
Seizures & - & 1 & - & - & 1 \\
Oculomotor paralysis & - & - & - & - & 1 \\
None & - & - & - & 1 & 4 \\
\hline
\end{tabular}


ICME-D-15-01605_R2 clean copy. Luyt et al., Brain injury during VV-ECMO

Table 3. Univariable and Multivariable Analyses of Factors Associated With Intracranial Bleeding (Excluding Microbleeds) on VV-ECMO

\begin{tabular}{lcc}
\hline & Univariable Analysis & Cox Analysis \\
Factor & OR [95\% CI] & HR [95\% CI] \\
\hline Age $>46$ yr & $1.91[0.51-7.10]$ & \\
Female sex & $2.02[0.55-7.41]$ \\
SAPS II score at ICU admission $\geq 70$ & $1.16[0.32-4.19]$ \\
Body mass index $>26$ & $0.47[0.1-1.96]$ \\
McCabe \& Jackson comorbidity score $\geq 2$ & $0.46[0.09-2.24]$ \\
MV duration before ECMO $>5$ days & $1.68[0.45-6.24]$ \\
Organ failure at ECMO initiation ${ }^{a}$ & \\
Cardiovascular & $0.73[0.15-3.60]$ \\
Hepatic & $2.74[0.69-10.95]$ \\
Renal & $5.80[1.18-28.47]$ \\
Hematological & $0.81[0.09-6.83]$ \\
Neurological & $1.05[0.21-5.25]$ \\
\end{tabular}

Gas exchange change

$$
\begin{aligned}
& \text { Arterial } \mathrm{pH}>0.2^{\mathrm{b}} \quad 2.34[0.61-8.89] \\
& \mathrm{PaO}_{2}>50 \mathrm{mmHg}^{\mathrm{b}} \quad 4.44[1.16-17.03] \\
& \mathrm{PaCO}_{2}<-27 \mathrm{mmHg}^{\mathrm{b}} \quad 5.95[1.20-29.52] \quad 6.02[1.28-28.57]
\end{aligned}
$$

Renal replacement therapy $\quad 1.26[0.34-4.68]$

Hemostasis disorders during ECMO
Platelets $<20 \times 10^{9} / \mathrm{L}$
$1.31[0.26-6.62]$
Prothrombin time $<30 \%{ }^{\mathrm{c}}$, n $(\%)$
$0.52[0.06-4.33]$
Fibrinogen, $<1.5 \mathrm{~g} / \mathrm{L}$
$0.76[0.15-3.76]$ 
ICME-D-15-01605_R2 clean copy. Luyt et al., Brain injury during VV-ECMO

Anticoagulant overdose

Abbreviations: SAPS, Simplified Acute Physiology Score; ICU, intensive care unit; MV, mechanical ventilation; VV-ECMO, venovenous-extracorporeal membrane oxygenation. ${ }^{a}$ Organ failure was deemed present when the corresponding Sepsis-related Organ Failure Assessment score was $>2$.

${ }^{\mathrm{b}}$ Defined as the post-ECMO $\mathrm{pH}, \mathrm{PaCO}_{2}$ or $\mathrm{PaO}_{2}$ value - the pre-ECMO $\mathrm{pH}, \mathrm{PaCO}_{2}$ or $\mathrm{PaO}_{2}$ value.

${ }^{c}$ Expressed as percentage of the standard value. 
ICME-D-15-01605_R2 clean copy. Luyt et al., Brain injury during VV-ECMO

Table 4. Hemostasis Parameters of Patients on Venovenous-Extracorporeal Membrane Oxygenation with Intracranial Bleeding During the 3 Days Before the Brain Haemorrhage

\section{Patients with Intracranial}

\section{Parameter}

$$
\text { Bleeding }(n=10)^{\mathrm{a}}
$$

aPTT, patient-to-normal value ratio ${ }^{\mathrm{b}}$

$1.14[1.1-1.7]$

Anti-Xa activity, IU/L ${ }^{\mathrm{b}}$

$0.1[0.1-0.1]$

Platelet count, $\times 10^{9} / \mathrm{L}^{\mathrm{c}}$

$84[29-135]$

Fibrinogen, $g / \mathrm{L}^{\mathrm{c}}$

$2.65[2-5.6]]$

Heparin dose, IU/24 h ${ }^{\mathrm{b}}$

$2,750[0-10,000]$

Abbreviation: aPTT, activated partial thrombin time.

${ }^{\text {a }}$ Values are expressed as median $\left[25^{\text {th }}-75^{\text {th }}\right.$ interquartile range $]$.

${ }^{\mathrm{b}}$ Highest value.

${ }^{c}$ Lowest value. 
Table 5. Studies on Neurological Injuries in Patients on ECMO Support Included in the Systematic Review

\begin{tabular}{|c|c|c|c|c|c|c|c|}
\hline \multirow[b]{2}{*}{ Reference } & \multirow{2}{*}{$\begin{array}{l}\text { Study } \\
\text { Design }\end{array}$} & \multirow{2}{*}{$\begin{array}{l}\text { No. of } \\
\text { Patients }\end{array}$} & \multicolumn{2}{|l|}{ Clinical Outcome } & \multirow{2}{*}{$\begin{array}{l}\text { Hemostasis } \\
\text { Disorders }\end{array}$} & \multirow{2}{*}{$\begin{array}{l}\text { Anticoagulant } \\
\text { Use }\end{array}$} & \multirow{2}{*}{$\begin{array}{l}\text { ECMO-Brain } \\
\text { Injury Interval }\end{array}$} \\
\hline & & & Neurological Complications & Deaths & & & \\
\hline \multirow[t]{4}{*}{ Kolla [22] } & Cohort & 100: $65 \mathrm{VV}-$ & $10(10 \%)^{\mathrm{a}}:$ & & NR & NR & NR \\
\hline & & ECMO; 11 VA- & 2 ischemic strokes & $2 / 2$ & & & \\
\hline & & ECMO; 34 with & 2 cerebral hemorrhages & $2 / 2$ & & & \\
\hline & & both & 6 brain deaths & $6 / 6$ & & & \\
\hline \multirow[t]{4}{*}{ Linden [23] } & Cohort & 17: 8 VV-ECMO; & $3(18 \%)^{\mathrm{a}}:$ & & NR & NR & NR \\
\hline & & 7 VA-ECMO; 2 & 1 cerebral edema & $1 / 1$ & & & \\
\hline & & with both & 1 cerebral bleeding & $1 / 1$ & & & \\
\hline & & & 1 ischemic stroke & $1 / 1$ & & & \\
\hline \multirow[t]{3}{*}{ Mols [24] } & Cohort & 62: all VV-ECMO & $2(3 \%):$ & & & & \\
\hline & & & 1 cerebral bleeding & $1 / 1$ & & & \\
\hline & & & 1 brain death & $1 / 1$ & & & \\
\hline Hemmila & Cohort & 255: $168 \mathrm{VV}-$ & $37(15 \%)^{\mathrm{a}}:$ & & NR & NR & NR \\
\hline [25] & & ECMO; 47 VA- & 14 ischemic strokes & $11 / 14$ & & & \\
\hline
\end{tabular}


ICME-D-15-01605_R2 clean copy. Luyt et al., Brain injury during VV-ECMO

$\begin{array}{llc}\text { ECMO; } 40 \text { with } & 9 \text { brain deaths } & 9 / 9 \\ \text { both } & 7 \text { cerebral bleeds } & 6 / 7 \\ & 7 \text { seizures } & 4 / 7\end{array}$

$\begin{array}{lll}\text { Brogan [26] Registry } & \text { 1473: } 703 \text { VV- } & 136(9 \%)^{\mathrm{a}} \text { : } \\ & \text { ECMO; 297 VA- } \quad 64 \text { cerebral strokes or bleeds } \\ & \text { ECMO; } 50 \text { with } \quad 72 \text { brain deaths } \\ & \text { both; } 423 \\ & \text { unknown } \\ \text { Peek [27] RCT } \quad 90 \text { VV-ECMO NR } & \\ & & \text { arm: } 65 \text { received } \\ & & \end{array}$

Davies [3] Cohort 68 with H1N1 flu: $6(9 \%)$ cerebral bleeds

4/90 died of NR NR
neurological
disorders

63 VV-ECMO; 5

VA-ECMO

Noah [28] Cohort $69 \mathrm{VV}$-ECMO for $8(12 \%)$ cerebral bleeds

$8 / 8$

NR

NR

H1N1 flu 
ICME-D-15-01605_R2 clean copy. Luyt et al., Brain injury during VV-ECMO

\begin{tabular}{|c|c|c|c|c|c|c|c|}
\hline Patroniti & Cohort & 60: 59 VV-ECMO; & $2(3 \%)^{\mathrm{a}}:$ & & NR & NR & \\
\hline \multirow[t]{2}{*}{ [29] } & & $1 \mathrm{VA-ECMO}$ & $1(2 \%)$ cerebral bleeding & $1 / 1$ & & & 2 days \\
\hline & & & $1 \mathrm{NR}$ & & & & NA \\
\hline \multirow[t]{3}{*}{ Pham [30] } & Cohort & 123:107 VV- & 5 cerebral bleeds $(4 \%)^{\mathrm{a}}$ & $5 / 5$ & NR & NR & NR \\
\hline & & ECMO; 16 VA- & & & & & \\
\hline & & ECMO & & & & & \\
\hline \multirow[t]{3}{*}{ Lindskov } & Cohort & 124: $110 \mathrm{VV}-$ & NR & 9 fatal cerebral & NR & NR & NR \\
\hline & & ECMO; 14 VA- & & infarcts with & & & \\
\hline & & ECMO & & hemorrhage & & & \\
\hline Michaels & Cohort & 12: 7 VV-ECMO; & 3 ischemic strokes & $3 / 3$ & $\mathrm{NR}$ & NR & NR \\
\hline$[32]$ & & 5 VA-ECMO & 1 ischemic brain injury & $1 / 1$ & & & \\
\hline \multirow[t]{2}{*}{ Roch [33] } & Cohort & 85: 77 VV-ECMO; & $2(2 \%)$ cerebral bleeds ${ }^{a}$ & $2 / 2$ & NR & NR & NR \\
\hline & & 8 VA-ECMO & & & & & \\
\hline $\mathrm{Ng}[34]$ & Cohort & $31 \mathrm{VV}-\mathrm{ECMO}$ & $1(3 \%)$ cerebral bleeding & $1 / 1$ & NR & NR & NR \\
\hline Kon [35] & Cohort & $55 \mathrm{VV}-\mathrm{ECMO}$ & 4 cerebral bleeds & NR & NR & NR & NR \\
\hline Gray [36] & Cohort & $353^{\mathrm{b}}: 262 \mathrm{VV}-$ & 16 cerebral bleeds or infarctions ${ }^{a}$ & $14 / 16$ & NR & NR & NR \\
\hline
\end{tabular}


ICME-D-15-01605_R2 clean copy. Luyt et al., Brain injury during VV-ECMO

ECMO; 91 VA-

ECMO

Abbreviations: VA, venoarterial; VV, venovenous; ECMO, extracorporeal membrane oxygenation; NR, not reported; RCT, randomizedcontrolled trial.

${ }^{a}$ Because the authors of these studies did not differentiate between VV- and VA-ECMO patients, the exact frequency of neurological complications occurring on VV-ECMO cannot be calculated.

${ }^{\mathrm{b}} 353$ adults received ECMO support for acute respiratory distress syndrome among a series 2000 adults and pediatric patients who received VAor VV-ECMO for cardiac or respiratory reasons. 


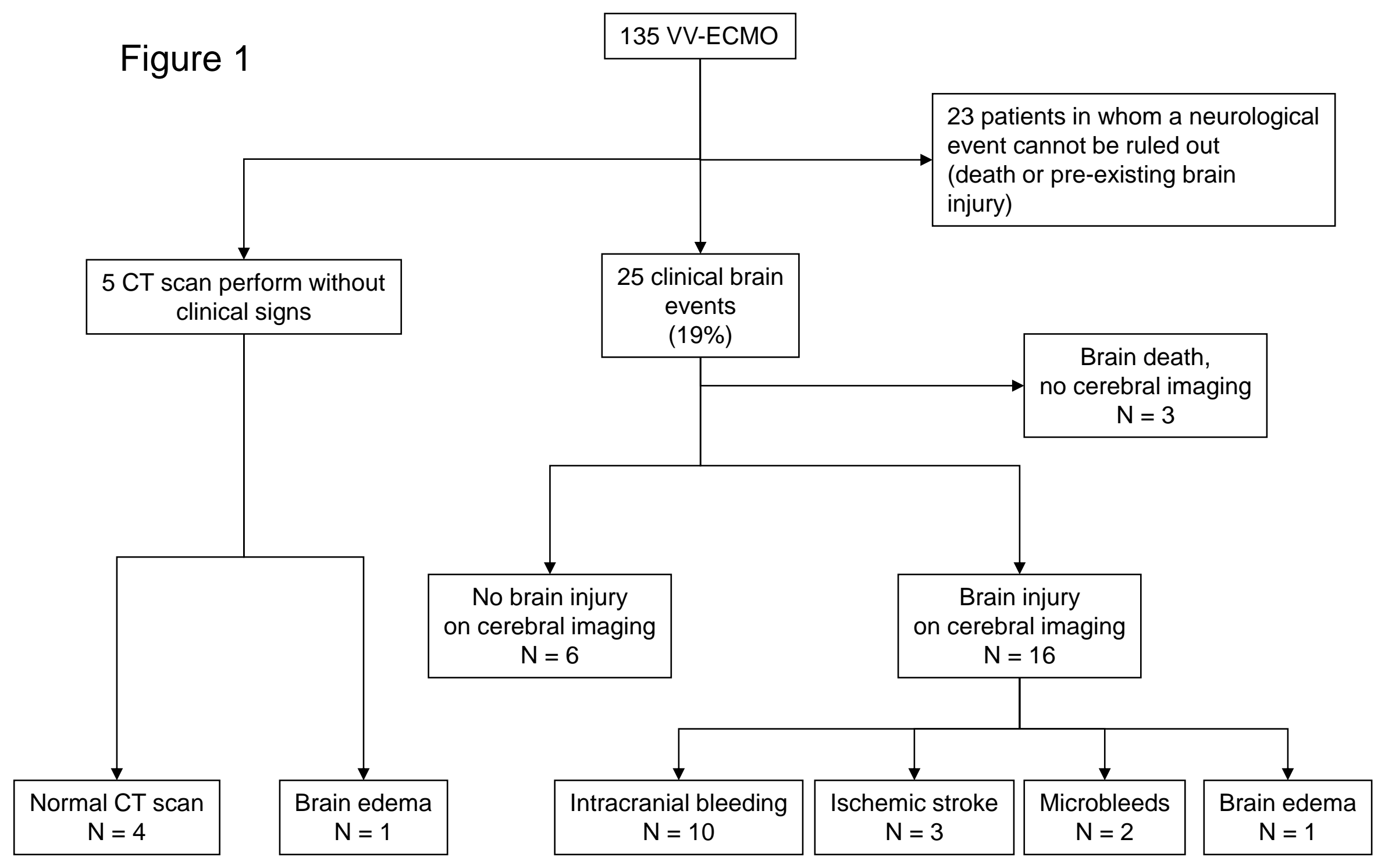


Figure 2
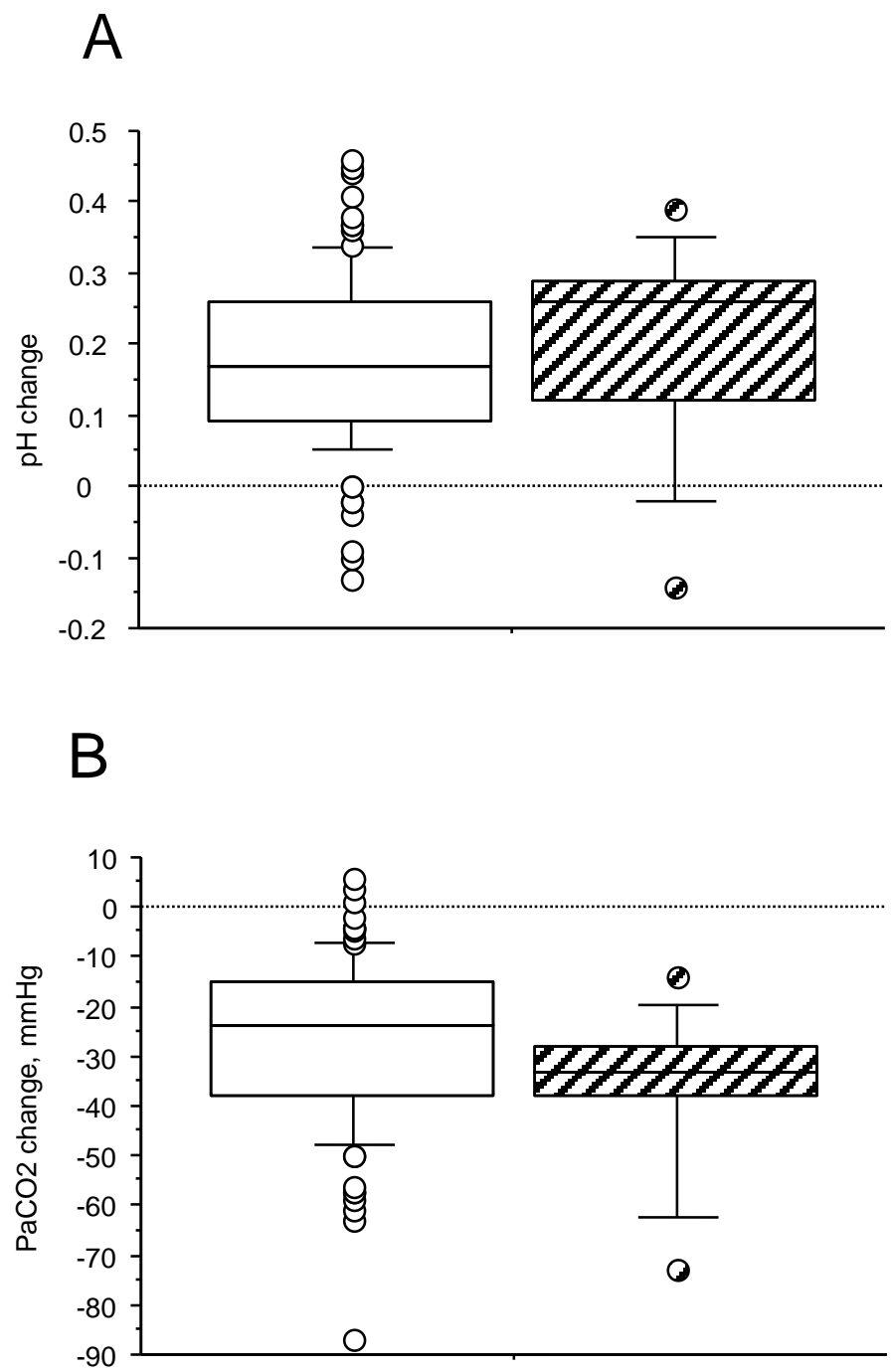

C

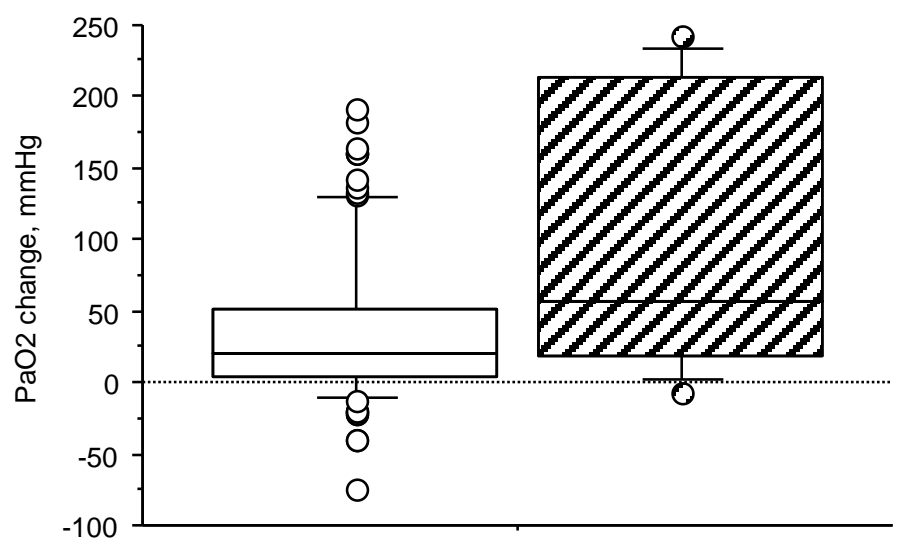

